\title{
The Metabolic Clearance Rate of Progesterone in Males and Ovariectomized Females*
}

\author{
B. Little, $†$ J. F. Tait, $\ddagger$ S. A. S. Tait, and F. Erlen meyer \\ (From the Department of Obstetrics and Gynecology, Harvard Medical School, and the Sears \\ Surgical Laboratory, Boston City Hospital, Boston, Mass.; and the Worcester Founda- \\ tion for Experimental Biology, Shrewsbury, Mass.)
}

The metabolic clearance rate (MCR) of a steroid hormone, which is probably most generally defined as the volume of blood cleared completely and irreversibly of steroid in unit time, determines the relationship between plasma production rate and plasma concentration (1). A knowledge of its value may also be important in predicting some of the characteristics of any control system (1-3).

It can be shown that after a single injection or continuous infusion of radioactive steroid, the metabolic clearance rate can be calculated as the reciprocal of the integrated plasma concentration of radioactivity measured specifically as the hormone (1). If this integration is performed correctly, the two methods should give the same value for MCR, and a comparison of the values obtained therefore serves as a check on this and other technical requirements for the validity of the calculation $(1,4)$.

In the studies described here, the MCR of progesterone has been measured by application of the single injection and continuous infusion methods in ovariectomized females and in males. Information on volumes of distribution has also been obtained after single injection.

\section{Methods}

The subjects were normal males and postoperative ovariectomized females. The males were volunteers 25

* Submitted for publication July 1, 1964 ; accepted February 24, 1966.

This work was supported by U. S. Public Health Service grants AM-03179, AM-05300, and HD-00390 and Atomic Energy Commission contract AT(30-1)-918. Some of the results were presented at the 44th Meeting of the Endocrine Society, June 1962.

$\dagger$ Address requests for reprints to Dr. Brian Little, Dept. of Obstetrics and Gynecology, Cleveland Metropolitan General Hospital, 3395 Scranton Road, Cleveland, Ohio 44109.

$\ddagger$ Holder of U. S. Public Health Service Career Award GM-K6-18322. to 35 years of age normally active up to the time of the test. Females without ovaries were patients studied at least 6 days after the operation of complete hysterectomy and bilateral salpingo-oophorectomy. They were studied on the gynecology wards of the Boston City Hospital. All were fasting and recumbent at the time of the test.

Progesterone-4- ${ }^{14} \mathrm{C},{ }^{1}$ progesterone- $7 \alpha-{ }^{8} \mathrm{H},{ }^{2}$ and progesterone, ${ }^{3}$ which had been obtained commercially, were fractionated by partition column chromatography before use. Progesterone-7 $\alpha-{ }^{3} \mathrm{H}$ was stored at a concentration of 11 $\mu \mathrm{c}(1.7 \mu \mathrm{g})$ per $\mathrm{ml}$ in ethanol and checked at regular intervals for radiochemical purity.

Ethyl acetate was prepared by shaking it with an excess of sodium bicarbonate, filtering and washing with an equal volume of water, and filtering again through sodium sulfate anhydrous $\left(\mathrm{Na}_{2} \mathrm{SO}_{4}\right)$ to eliminate all water. Tests of ethyl acetate with acidified $1 \%$ potassium iodine demonstrated the absence of peroxides. Methanol, 2,2,4-trimethylpentane, and toluene were reagent grade and were all redistilled before use. Celite was prepared by washing it with acid, then with distilled water to neutrality; finally, it was washed with methanol and dried in an oven at $60^{\circ} \mathrm{C}$.

Single injection. In the single injection experiments, $2.2 \mu \mathrm{c}(0.2 \mathrm{ml})$ of progesterone- $7 \alpha^{-3} \mathrm{H}$ in ethanol was added to $11.0 \mathrm{ml}$ of normal saline $(2.0 \%$ ethanol solution). Ten $\mathrm{ml}$ of this solution containing $2.0 \mu \mathrm{c}(0.3 \mu \mathrm{g})$ progesterone-7 $\alpha^{-}{ }^{8} \mathrm{H}$ was injected into the subject's antecubital vein at about 8 a.m. Blood was withdrawn from the antecubital vein of the opposite arm. In three subjects $(3,4$, and 15$)$ it was taken at $2.5,5.0,7.5,10,15$, and 20 minutes after the initial injection. In six subjects $(9,10,11,13,16$, and 17) samples were drawn at $2.5,5.0,7.5,10,15,20$, and 30 minutes after the injection. In two of these subjects (9 and 17) additional samples were drawn at 50 minutes $(100 \mathrm{ml}$ of blood) and 70 minutes ( $200 \mathrm{ml}$ of blood).

In repeated control experiments we found that $9 \pm 1.8$ (SD) \% (15 experiments) of the progesterone- ${ }^{8} \mathrm{H}$ was adsorbed by the syringe at this concentration of ethanol in saline, and the calculated values were corrected by this factor.

1 Picker X-ray Co., White Plains, N. Y.

2 New England Nuclear. Corp., Boston, Mass.

3 Steraloids, New York, N. Y. 
Continuous infusion. In ten male subjects and eleven ovariectomized females, the metabolic clearance rate was determined by the method of continuous infusion.

In fasting subjects an initial priming injection was given at 8 a.m. In five males and five females this injection was prepared as follows: into $11.0 \mathrm{ml}$ of $20 \%$ ethanol in normal saline ( $\mathrm{vol}: \mathrm{vol}$ ) was added $0.075 \mathrm{ml}$ of a solution of progesterone-7- ${ }^{8} \mathrm{H}$ in ethanol $(0.82 \mu \mathrm{c})$. Ten $\mathrm{ml}$ of this solution $(0.75 \mu \mathrm{c}, 0.11 \mu \mathrm{g})$ was injected into the antecubital vein. Ten minutes later a continuous infusion of progesterone- $7-{ }^{8} \mathrm{H}$ in $20 \%$ ethanol in normal saline was begun in the same arm. The injection solution was $42.0 \mathrm{ml}$ of $20 \%$ ethanol in normal saline into which had been dissolved $0.225 \mathrm{ml}$ of a solution of progesterone- $7-{ }^{3} \mathrm{H}$ in ethanol $(2.48 \mu \mathrm{c}, 0.37 \mu \mathrm{g})$. In five males and six females $0.05 \mathrm{ml}$ of a solution of progesterone-7- ${ }^{3} \mathrm{H}(0.55 \mu \mathrm{c}, 0.0082 \mu \mathrm{g})$ was added to $11.0 \mathrm{ml}$ $2.0 \%$ ethanol in saline as initial injection. The continuous infusion was $42.0 \mathrm{ml}$ of $0.4 \%$ ethanol in saline in which had been dissolved progesterone-7 $\alpha{ }^{-}{ }^{8} \mathrm{H}$ (1.65 $\mu \mathrm{c}$, $0.24 \mu \mathrm{g}$ ). This was infused by a constant infusion pump 4 from a $50-\mathrm{ml}$ Luer-Lok syringe. It was attached to a no. 20 bore needle in the patient's vein by an R-33 5 polyethylene adapter that contained about $1.5 \mathrm{ml}$. The machine was run at a rate of $0.382 \mathrm{ml}$ per minute infusing $1.5 \mu \mathrm{c}$ over a period of 100 minutes at a rate equivalent to about $21.6 \mu \mathrm{c}$ per day. Samples were drawn at 10,85 , 95 , and 105 minutes after the start of the experiment.

In nine control experiments in which an infusion solution of $0.4 \%$ ethanol in saline was used, we found that $40 \pm 2$ (SD) \% of the initial concentration of progesterone $-{ }^{3} \mathrm{H}$ emerged from the needle, and we corrected the values by this factor, as we also found that the effluent concentration was constant during the whole course of the infusion. When a solution of $20 \%$ ethanol in saline was used, $50 \pm 4$ (SD) \% of the progesterone emerged. This was measured during ten MCR by continuous infusion $\left(M^{2} R^{r}\right)$ determinations. In practice for these latter experiments, the amount infused was estimated directly (at the start and end of the infusion) by counting $0.6 \mathrm{ml}$ of the ethanolic solution of saline with $10 \mathrm{ml}$ of the usual scintillation fluid plus $6 \mathrm{ml}$ ethanol. Appropriate standards counted in the same scintillation mixture of solutions were counted simultaneously. The mean concentration at the start and end of the infusion that was not systematically different was taken to calculate the rate of infusion of progesterone $-{ }^{8} \mathrm{H}$.

In five male subjects who were studied by the continuous infusion method, both plasma and blood samples were estimated. The blood was hemolyzed and extracted in the same manner as previously described (4).

In two volunteers (47 and 51 ), one an ovariectomized female and one a male, an infusion was given over a period of 500 minutes. After a priming injection of $1.75 \mu \mathrm{c}$ of progesterone- $7-{ }^{3} \mathrm{H}$ dissolved in $10 \mathrm{ml}$ of $0.4 \%$ ethanol in normal saline, continuous infusion was administered. The continuous infusion of the ovariectomized female (no. 47) was $42.0 \mathrm{ml}$ of $0.4 \%$ ethanol in normal saline

\footnotetext{
${ }^{4}$ Harvard Instrument Co., Dover, Mass.
}

5 Baxter Laboratories, Morton Grove, Ill. into which had been dissolved $0.75 \mathrm{ml}$ of progesterone$7-{ }^{8} \mathrm{H}$ of the standard solution $(8.25 \mu \mathrm{c})$. It was infused at a rate of $14.6 \mathrm{~m} \mu \mathrm{c}$ per minute $(20.9 \mu \mathrm{c}$ per day). In the male (no. 51) the infusion contained $5.5 \mu \mathrm{c}$ and was run at about $11.0 \mathrm{~m} \mu \mathrm{c}$ per minute (15.84 $\mu \mathrm{c}$ per day).

In all experiments $50-\mathrm{ml}$ samples of blood were drawn from the opposite antecubital vein in heparinized syringes. The blood was immediately centrifuged, and the plasma was added to tubes containing a dry sample of progesterone-4- ${ }^{14} \mathrm{C}$ of low specific activity [usually 70 cpm (140 dpm, $0.07 \mu \mathrm{g}$ ) and $200 \mu \mathrm{g}$ per $20 \mathrm{ml}$ of plasma]. The plasma was then extracted with $4 \times 1.3$ vol of ethyl acetate. The combined solvent extracts were washed once with water and taken to dryness in vacuo. The residue was transferred to a partition column in $1 \mathrm{ml}+$ $2 \times 0.5 \mathrm{ml}$ mobile phase. The column $60 \mathrm{~cm}$ long contained $25 \mathrm{~g}$ Celite and $12.5 \mathrm{ml}$ of the stationary phase methanol: water, $4: 1$ (vol:vol) and was developed with 2,2,4-trimethylpentane as the mobile phase; 5-ml fractions were collected. The holdback volume of the column was approximately $25 \mathrm{ml}$. One-half $\mathrm{ml}$ of fractions 10 to 15 (counted from the time of application of the extract) was dried under nitrogen and applied to Whatman 1 paper and developed in a ligroine, methanol: water, 9:1 (vol:vol) system for 1 to 2 hours. These papers were scanned in the ultraviolet light to determine which fractions contained progesterone. Usually progesterone appeared in fractions 11,12 , and 13 . The three fractions were pooled and added to scintillation vials. The three fractions more polar and the three less polar in certain experiments were also pooled into two scintillator vials. All were dried in a vacuum desiccator overnight. Ten $\mathrm{ml}$ of scintillation fluid (4 $\mathrm{g}$ PPO [2,5-diphenyloxazole] $=100 \mathrm{mg}$ POPOP [1,4-bis-2-(5-phenyloxazolyl benzene)] per $\mathrm{L}$ of toluene: methanol, $98: 2$ [vol: vol]) was added. The vials were then assayed for ${ }^{8} \mathrm{H}$ and ${ }^{14} \mathrm{C}$ in an automatic liquid scintillator. ${ }^{6}$ The samples, including appropriate experimental standards and blanks for each column, were counted for at least four 30 -minute periods at each high voltage position (taps 3 and 8). These taps were just off the balance point for each isotope, where the contribution of ${ }^{14} \mathrm{C}$ radioactivity was minimal in the ${ }^{3} \mathrm{H}$ range. The counting rates of ${ }^{3} \mathrm{H}$ and ${ }^{14} \mathrm{C}$ estimated this way gave a value for the initial tritium content of the plasma, present specifically as progesterone, and corrected for losses during isolation. Accuracy was within $\pm 6 \%$ including counting errors. The fractions on either side of the progesterone peak were assayed in all the initial experiments. In most experiments the ${ }^{3} \mathrm{H}$ radioactivity in side fractions was negligible. When it was greater than $5 \mathrm{cpm}$, the ${ }^{3} \mathrm{H} /{ }^{14} \mathrm{C}$ ratio of the side fraction was the same as the ratio for the peak fraction. The columns were reused after passing about $300 \mathrm{ml}$ of mobile phase over them. However, each column was rebuilt about every 6 to 12 weeks.

Specificity was considered valid because of the coincidence of progesterone- ${ }^{8} \mathrm{H}$, progesterone $-{ }^{14} \mathrm{C}$, and inert progesterone. Also, side fractions contained little ultra-

6 Tri-Carb model 314X, Packard Instrument Co., La Grange, Ill. 
violet-absorbing material, but ${ }^{3} \mathrm{H} /{ }^{14} \mathrm{C}$ ratios were equal to peak fractions.

In the earlier experiments the three peak tubes and the three tubes each more polar and less polar were compared. Where sufficient radioactivity was present, the ${ }^{3} \mathrm{H} /{ }^{14} \mathrm{C}$ ratios in all three groups were shown to be equal. The three peak tubes were examined individually, and the ratios among ultraviolet adsorption and ${ }^{3} \mathrm{H}$ and ${ }^{14} \mathrm{C}$ values were shown to be equal.

In two experiments $2.5 \mu \mathrm{c}$ of progesterone- $7-{ }^{3} \mathrm{H}$ was administered to ovariectomized women as a priming dose followed by $7.5 \mu \mathrm{c}$ progesterone- $7-^{8} \mathrm{H}$ infused over 100 minutes. After 95 minutes blood was drawn sufficient to obtain 4- $\times 20-\mathrm{ml}$ samples of plasma to which was added the recovery standard progesterone-4- ${ }^{14} \mathrm{C}$. Each was extracted, pooled, and separated on two chromatographic columns in the usual manner. The three peak progesterone tubes from each column were pooled, and a sample was taken for counting. In one experiment the remainder was then dried and incubated with $20 \beta$-hydroxysteroid dehydrogenase 7 for 2 hours in $0.2 \mathrm{M}$ phosphate buffer to which $0.005 \mathrm{M}$ EDTA had been added with $1.0 \mathrm{mg} \mathrm{DPNH}$ as cofactor. The incubate was extracted with ether, and the ether was taken to dryness. The residue, after the addition of authentic $20 \beta$-hydroxy4-pregnen, 3-one, was placed on a Celite column in the usual manner (cyclohexane:70\% methanol). The tubes (no. 17, 18, and 19) containing the authentic 20 $\beta$-hydroxy-4-pregnen, 3-one were counted in the usual manner. In the other experiment the progesterone was reacted with $20 \alpha$-hydroxysteroid dehydrogenase (5) in a similar manner, employing a TPNH-generating system. At the same time, controls were incubated, using as substrate equivalent counts of the injection solution of progesterone$7-{ }^{3} \mathrm{H}$ and recovery standard progesterone $-4-{ }^{14} \mathrm{C}$, and reacted with the hydroxysteroid dehydrogenase in the same manner. In both experiments the clearance rates calculated from the ${ }^{3} \mathrm{H} /{ }^{14} \mathrm{C}$ ratios of the $20 \alpha$ and $20 \beta$ reduced derivatives were the same as those calculated from the initial ratio of the progesterone from the column using the appropriate standards for all three calculations.

In 18 experiments, 73 determinations, the recovery of ${ }^{14} \mathrm{C}$ had a mean value of $50.1 \% \pm 0.17$ (SE). The coefficient of variation was $9 \%$.

Theory. The metabolic clearance rate of progesterone from the plasma is defined as the volume of plasma from which the steroid is completely and irreversibly removed in unit time. The values expressed are then the plasma metabolic clearance rate (MCR plasma). The mathematical calculation of $\mathrm{MCR}$ as derived by Tait and Burstein (3) in analogous treatment to that of Hamilton and Remington (6) states:

If $\mathrm{x}^{\prime}$ is the radioactive concentration of the hormone, then $\mathrm{MCR} \cdot \mathrm{x}^{\prime} \cdot \mathrm{dt}$ is the radioactivity cleared $(\mathrm{dR})$ in the small time interval $(\mathrm{dt})$. Then $\mathrm{MCR} \cdot \mathrm{x}^{\prime} \cdot \mathrm{dt}=\mathrm{dR}$, and

$$
\int_{0}^{\infty} \mathrm{MCR} \cdot \mathrm{x}^{\prime} \cdot \mathrm{dt}=\mathrm{Rs},
$$

${ }^{7}$ Sigma Chemical Co., St. Louis, Mo. where $\mathrm{Rs}=$ total radioactivity injected into blood.

All radioactive measurements are conveniently expressed as fractions of dose injected. Then $\mathrm{Rs}=1$, and

$$
\int_{0}^{\infty} \mathrm{MCR} \cdot \mathrm{x}^{\prime} \cdot \mathrm{dt}=1
$$

In the steady state where MCR is constant,

$$
\operatorname{MCR} \int_{0}^{\infty} x^{\prime} \cdot d t=1 ; \quad \operatorname{MCR}=\frac{1}{\int_{0}^{\infty} x^{\prime} \cdot d t .}
$$

The amount of steroid cleared from the blood in unit time equals MCR $\cdot i$, where $i$ is the blood nonisotopic steroid concentration. In the steady state the rate of clearance will be equal to the rate of entry as the concentration in the blood is constant. Therefore, the production rate $\left(\mathrm{P}^{\mathrm{I}}\right)$ in the steady state is equal to the amount of steroid cleared: $\mathrm{P}^{\mathrm{I}}=\mathrm{MCR} \cdot \mathrm{i}$. From the determination of MCR and knowledge of blood concentration the production rate of progesterone may be determined. If there is more than one compartment with secretion both in the inner and outer compartments, the production rate is the secretion directly into the inner compartment (i.e., the compartment that is measured) plus the proportion of new steroid secreted into the outer compartments that enters the blood (7). The inner compartment would comprise that steroid which is in rapid equilibrium with the blood, and the outer compartments, steroid that is in slower equilibrium. These compartments do not necessarily correspond with any anatomical boundaries. By this definition, "production" would include progesterone directly released into the appropriate compartment from the endocrine glands plus progesterone synthesized in the same compartment from intermediates, e.g., as regards the inner compartment, this could include progesterone released by the adrenals and gonads plus progesterone converted from pregnenolone in the liver that emerges into the general circulation [cf. discussion in (1)].

The MCR can be measured after a rapid single injection or a continuous infusion. If the production rate is known, the MCR may be calculated indirectly from the values of blood concentration: $M C R=P^{1} / i$.

For all steroids so far investigated the disappearance curve of radioactive concentration in plasma (measured specifically as the hormone) must be represented by at least two exponentials :

$$
x^{\prime}=A^{\prime} e^{-\alpha t}+B^{\prime} e^{-\beta t}+C^{\prime} e^{-\gamma t} \ldots
$$

Therefore, the metabolism and transport of the steroid must be described by at least two compartments. To calculate the metabolic clearance rate after single injection $\left(\mathrm{MCR}^{\mathrm{R}}\right)$, then :

$$
\operatorname{MCR}^{R}=\frac{1}{\int_{0}^{\infty} x^{\prime} \cdot d t}=\frac{1}{\frac{\mathrm{A}^{\prime}}{\alpha}+\frac{\mathrm{B}^{\prime}}{\beta}+\frac{\mathrm{C}^{\prime}}{\gamma} \cdots}
$$

If only two compartments are used, the disappearance curve is expressed as two exponentials $\mathrm{MCR}^{\mathrm{R}}=\alpha \beta$ / $\left(A^{\prime} \beta+B^{\prime} \alpha\right)$. The first part of this curve when extrapolated against time gives a value for the initial volume 
of disappearance or inner compartment $\left(\mathrm{V}^{\mathrm{I}}\right)$. The estimation of the outer volume $\left(\mathrm{V}^{\mathbf{Q}}\right)$ is more difficult. The second limb of the curve represents the sum of four unknown influences (the metabolism in the inner and outer compartments and the exchange in both directions between the compartments). To be solved mathematically, metabolism must be considered to be exclusively in either the inner or outer compartment (8). If metabolism in the inner compartment is assumed to be zero $(\mathrm{a}=0)$, then:

$$
\mathrm{V}_{\mathrm{a}=0} \mathrm{Q}=\frac{\mathrm{A}^{\prime} \alpha+\mathrm{B}^{\prime} \beta}{\left(\mathrm{A}^{\prime}+\mathrm{B}^{\prime}\right)\left(\mathrm{A}^{\prime} \beta+\mathrm{B}^{\prime} \alpha\right)}
$$

and if the metabolism in the outer compartment is assumed to be zero $(e=0)$, then :

$$
\mathrm{V}_{\mathrm{e}=0} \mathrm{Q}=\frac{\mathrm{A}^{\prime} \mathrm{B}^{\prime}}{\left(\mathrm{A}^{\prime}+\mathrm{B}^{\prime}\right)} \cdot \frac{(\alpha-\beta)^{2}}{\left(\mathrm{~A}^{\prime} \boldsymbol{\beta}+\mathrm{B}^{\prime} \alpha\right)^{2}} .
$$

In the single injection experiments, values were plotted semilogarithmically. The values for $M_{C R}{ }^{R}$ have been determined from the equation $\alpha \beta /\left(\mathrm{A}^{\prime} \beta+\mathrm{B}^{\prime} \alpha\right)$ (4), where $\alpha, \beta, \mathrm{A}^{\prime}$, and $\mathrm{B}^{\prime}$ have been determined from the lines of regression plotted as a double exponential curve with individual points fitted by the method of least squares. Values of $\alpha$ and $\mathrm{A}^{\prime}$ were obtained from plasma radioactive progesterone concentrations expressed as millimicrocuries per liter at 2.5, 5.0, and 7.5 minutes after subtracting the extrapolated values for the same times from the curve after 10 minutes extended back to the ordinate. Values at $10,15,20,30,50$, and 70 minutes were then fitted for the straight line disappearance obtained in each case. The values for $\beta$ and $B^{\prime}$ were determined in this manner; at least four points were used in this calculation for all subjects except 3,4 , and 15 , in whom only three points were used.

In the measurement of $\mathrm{MCR}^{\mathrm{r}}$ a priming dose of radioactivity was given to shorten the time necessary to at- tain constant radioactive concentration. After $10 \mathrm{~min}$ utes a continuous infusion of radioactivity of progesterone- $7-{ }^{3} \mathrm{H}$ was given. The infusion was given at a constant rate $(r)$ until the radioactive concentration was constant $\left(x_{c}^{\prime}\right)$ (at 85 to 105 minutes). For continuous infusion:

$$
\operatorname{MCR}^{r}=\frac{1}{\int_{0}^{\infty} x^{\prime} \cdot d t}=\frac{r}{x_{c}^{\prime}} .
$$

Plasma radioactive progesterone concentration was measured three times, at 10 -minute intervals, towards the end of the infusion. The $\mathrm{MCR}^{\mathbf{r}}$ was calculated from the mean of these three values. The coefficient of variation of the three values is expressed as standard deviation/ mean $\times 100 \%$. The estimate of error of $\mathrm{MCR}^{\mathrm{r}}$ is expressed as standard error $/$ mean $\times 100 \%$.

\section{Results}

The results are summarized in Tables I to VI. The clearance rates measured after infusion of saline with 0.4 or $20 \%$ ethanol calculated directly or indirectly are not significantly different $(\mathrm{p}>$ 0.01 for all results).

If the calculation of clearance rate by the method of continuous infusion is to be valid, the three final values of radioactive concentration from which the mean $\mathbf{x}_{\mathbf{c}}^{\prime}$ is determined must be constant. In both males and ovariectomized females in whom continuous infusion experiments have been performed, there is no significant trend among the three values in individual experiments. In the males the values at 85 minutes were $102 \pm 3.0$ (SE) \%,

TABLE I

\begin{tabular}{|c|c|c|c|c|c|c|c|c|c|c|c|c|c|}
\hline \multirow{2}{*}{$\begin{array}{l}\text { Sub- } \\
\text { jects }\end{array}$} & \multirow[b]{2}{*}{ Age } & \multirow[b]{2}{*}{ Height } & \multirow[b]{2}{*}{ Weight } & \multirow{2}{*}{$\underset{\text { tocrit }}{\text { Hema- }}$} & \multicolumn{4}{|c|}{ Time } & \multirow{2}{*}{$\begin{array}{c}\text { Mean of } \\
85^{\prime}, 95^{\prime} \text {, } \\
105^{\prime} \\
\left(x^{\prime}\right)\end{array}$} & \multirow{2}{*}{$\begin{array}{l}\text { Coef- } \\
\text { ficient } \\
\text { of vari- } \\
\text { ation* }\end{array}$} & \multirow{2}{*}{$\begin{array}{c}\text { Rate of } \\
\text { infu- } \\
\text { sion } \\
(n)\end{array}$} & \multirow{2}{*}{$\begin{array}{r}\text { MCRr } \\
\left(\frac{r}{x_{0}^{\prime}}\right)^{2}\end{array}$} & \multirow{2}{*}{$\begin{array}{c}\text { Error } \\
\text { of esti- } \\
\text { mate† }\end{array}$} \\
\hline & & & & & $10^{\prime}$ & $85^{\prime}$ & $95^{\prime}$ & $105^{\prime}$ & & & & & \\
\hline & years & inches & kg & $\%$ & \multicolumn{4}{|c|}{$c p m / L$} & & $\%$ & $c p m \times$ & $L / d a y$ & $\%$ \\
\hline $2 \mathrm{~A}$ & 28 & 68 & 65.9 & 45 & 6,583 & 4,635 & 4,162 & 4,310 & 4,369 & 5.5 & 8.02 & 1,834 & 3.2 \\
\hline $3 \mathrm{~A}$ & 27 & 69 & 90.9 & 45 & 3,231 & 1,842 & 1,754 & 1,913 & 1,836 & 4.3 & 4.92 & 2,682 & 2.5 \\
\hline $4 \mathrm{~A}$ & 31 & 73 & 90.9 & 44 & 4,874 & 2,717 & 2,463 & 2,727 & 2,636 & 5.7 & 5.04 & 1,910 & 3.3 \\
\hline $5 \mathrm{~A}$ & 28 & 68 & 77.3 & 43 & 4,599 & 2,406 & 2,725 & 2,698 & 2,610 & 6.8 & 4.80 & 1,838 & 3.9 \\
\hline $6 \mathrm{~A}$ & 30 & 67 & 65.9 & 44 & 3,538 & 3,141 & 3,204 & 3,074 & 3,140 & 3.1 & 5.20 & 1,656 & 1.8 \\
\hline $26 \ddagger$ & 26 & 66 & 68.1 & 40 & 2,477 & 2,105 & 2,537 & 2,275 & 2,305 & 9.4 & 4.00 & 1,736 & 5.4 \\
\hline $27 \ddagger$ & 25 & 74 & 84.5 & 45 & 1,895 & 1,714 & 1,542 & 1,641 & 1,632 & 5.3 & 4.00 & 2,452 & 3.1 \\
\hline $29 \ddagger$ & 26 & 72 & 86.4 & 44 & 2,833 & 2,365 & 2,199 & 2,481 & 2,348 & 6.0 & 3.87 & 1,647 & 3.5 \\
\hline $30 \ddagger$ & 25 & 72 & 75.0 & 44 & 1,440 & 1,292 & 1,425 & 1,517 & 1,411 & 8.0 & 3.95 & 2,799 & 4.6 \\
\hline $32 \ddagger$ & 28 & 69 & 75.0 & 48 & 1,705 & 1,809 & 1,600 & 1,842 & 1,750 & 7.4 & 3.95 & 2,257 & 4.3 \\
\hline Mean (10)§ & 27 & 69.8 & 78.0 & 44.2 & & & & & & 6.1 & 2,0 & $31 \pm 137$ & 3.6 \\
\hline
\end{tabular}

The measured and calculated values determining the metabolic clearance rate of progesterone from plasma $\left(M C R^{r}\right)$ in 10 males studied by the continuous infusion method

$* \mathrm{SD} /$ mean $\times 100 \%$.

$\dagger \mathrm{SE} / \mathrm{mean} \times 100 \%$;

$\$$ Parentheses denote number of subjects; \pm denotes standard error. 
TABLE II

The measured and calculated values determining the metabolic clearance rate of progesterone from plasma $\left(M C R^{\mathrm{r}}\right)$ in 11 ovariectomized females studied by the continuous infusion method

\begin{tabular}{|c|c|c|c|c|c|c|c|c|c|c|c|c|c|}
\hline \multirow[b]{2}{*}{ Subjects } & \multirow[b]{2}{*}{ Age } & \multirow{2}{*}{\multicolumn{2}{|c|}{ Height Weight }} & \multirow{2}{*}{$\underset{\text { tocrit }}{\text { Hema- }}$} & \multicolumn{4}{|c|}{ Time } & \multirow{2}{*}{$\begin{array}{l}\text { Mean of } \\
85^{\prime}, 95^{\prime} \text {, } \\
1^{\prime 05^{\prime}} \\
\left(x^{\prime} \circ\right)\end{array}$} & \multirow{2}{*}{$\begin{array}{l}\text { Coef- } \\
\text { ficient } \\
\text { of vari- } \\
\text { ation* }\end{array}$} & \multirow{2}{*}{$\begin{array}{l}\text { Rate of } \\
\text { infu- } \\
\text { sion } \\
\text { (r) }\end{array}$} & \multirow{2}{*}{$\begin{array}{c}\text { MCRr } \\
\left(\frac{r}{x_{0}^{\prime}}\right)\end{array}$} & \multirow{2}{*}{$\begin{array}{c}\text { Error of } \\
\text { esti- } \\
\text { mate }\end{array}$} \\
\hline & & & & & $10^{\prime}$ & $85^{\prime}$ & $95^{\prime}$ & $105^{\prime}$ & & & & & \\
\hline & years & inches & kg & $\%$ & \multicolumn{4}{|c|}{$c p m / L$} & & $\%$ & $\underset{10^{-6}}{c p m} \times$ & $L / d a y$ & $\%$ \\
\hline $8 \mathrm{~A}$ & 38 & 66 & 65.9 & 34 & 4,727 & 2,779 & 2,772 & 2,611 & 2,721 & 3.5 & 5.1 & 1,886 & 2.0 \\
\hline $13 \mathrm{~A}$ & 31 & 62 & 63.2 & 28 & 3,668 & 3,772 & 3,563 & 3,753 & 3,696 & 3.1 & 5.3 & 1,557 & 1.8 \\
\hline $14 \mathrm{~A}$ & 44 & 61 & 70.5 & 35 & 4,623 & 2,751 & 2,543 & 2,674 & 2,656 & 4.0 & 5.9 & 2,223 & 2.3 \\
\hline $15 \mathrm{~A}$ & 34 & 65 & 74.1 & 42 & 3,113 & 2,720 & 2,916 & 3,076 & 2,904 & 6.1 & 5.9 & 2,047 & 3.5 \\
\hline $16 \mathrm{~A}$ & 39 & 64 & 55.9 & 38 & 3,331 & 3,069 & 2,947 & 2,949 & 2,989 & 2.3 & 5.2 & 1,772 & 1.3 \\
\hline $28 \ddagger$ & 45 & 65 & 68.2 & 33 & 2,670 & 2,831 & 2,807 & 2,631 & 2,756 & 3.9 & 2.9 & 1,444 & 2.2 \\
\hline $34 \ddagger$ & 38 & 67 & 72.7 & 34 & 4,434 & 1,828 & 1,676 & 1,657 & 1,720 & 5.4 & 2.9 & 2,338 & 3.1 \\
\hline $35 \ddagger$ & 30 & 66 & 56.8 & 33 & 3,430 & 1,893 & 1,683 & 1,739 & 1,772 & 6.1 & 2.9 & 2,270 & 3.5 \\
\hline $36 t$ & 42 & 63 & 65.5 & 40 & 4,231 & 1,164 & 1,116 & 1,216 & 1,165 & 4.3 & 2.9 & 3,452 & 2.5 \\
\hline $37 \ddagger$ & 46 & 64 & 52.3 & 32 & 2,500 & 2,310 & 2,250 & 2,295 & 2,285 & 1.4 & 2.9 & 1,760 & 0.8 \\
\hline $38 \ddagger$ & 32 & 66 & 82.7 & 31 & 2,218 & 1,207 & 1,421 & 1,274 & 1,300 & 8.4 & 3.0 & 3,159 & 4.8 \\
\hline Mean (11)§ & 38 & 64 & 66.2 & 34.5 & & & & & & 4.4 & 2,17 & $3 \pm 175$ & 2.5 \\
\hline
\end{tabular}

$*$ SD/mean $\times 100 \%$

$\ddagger \mathrm{SE} / \mathrm{mean} \times 100 \%$. Parentheses denote number of subjects; \pm denotes standard error.

and the last values at 105 minutes were $105 \pm 2.0$ (SE) \% that of the midpoint (95 minutes). In ovariectomized females, the values at 85 minutes were $102 \pm 2.0$ (SE) \% and at 105 minutes 101 \pm 2.0 (SE) \% that of the 95-minute value.

The mean coefficient of variation of the three values used to determine the mean $\left(\mathbf{x}_{\mathbf{c}}^{\prime}\right)$ plasma radioactive progesterone concentration in the males was $6.1 \%$ (range, 3.1 to $9.4 \%$ ). The mean coefficient of variation in the ovariectomized females was $4.4 \%$ (range, 1.4 to $8.4 \%$ ). The mean error of the estimate in males was $3.6 \%$ (range, 1.8 to $5.4 \%$ ) and in ovariectomized females $2.5 \%$ (range, 0.8 to $4.8 \%$ ) (Tables I and II).

In two long infusions designed to demonstrate equilibrium over 8 hours there was no consistent trend of the values obtained either upward or down after 85 minutes. The coefficient of variation was 13.7 and $20 \%$ in one ovariectomized female (No. 47) and one male (No. 51), respectively. The constant plasma progesterone concentration during the long infusion and the constant values at 85,95 , and 105 minutes validate the method of continuous infusion to measure metabolic clearance rate in these subjects (Table III).

If the calculation of clearance rate by the single injection method is to be valid, the values when plotted semilogarithmically must show a straight line disappearance. In the two experiments (9 and 17) in which values were measured at 50 and
70 minutes, the straight line obtained between 10 and 30 minutes was shown to be maintained. Because large volumes of blood are required to obtain values at 50 minutes $(100 \mathrm{ml})$ and $70 \mathrm{~min}-$ utes $(200 \mathrm{ml})$, this cannot be done routinely to confirm the single injection method. A comparison of single injection with continuous infusion provides another test for straight line disappearance.

In the ten males studied by single injection the $\mathrm{MCR}^{\mathrm{R}}$ was $2,450 \pm 437$ (SE). In ten males studied by continuous infusion the $\mathrm{MCR}^{\mathrm{r}}$ was $2,081 \pm$ 137 (SE). There is no significant difference between these values $(p>0.05)$. A $16.5 \%$ difference $(p<0.05)$ would have been significant, but the difference was only $16 \%$. In 11 ovariectomized females studied by continuous infusion the $\mathrm{MCR}^{\mathrm{r}}$ was $2,173 \pm 175$ (SE), and in three ovariectomized females studied by the single injection method the $\mathrm{MCR}^{\mathrm{R}}$ was $2,428 \pm 322(\mathrm{SE})$. The difference of the means was $11 \%$, but this was not significant. A difference of $13 \%$ would have been necessary for a significant difference.

From all these considerations, either the continuous infusion or single injection method is valid. In pooling the data, however, the difference between single injection and continuous infusion borders on the significant $(p<.05>.025)$. As will be discussed later, the consistently higher mean values for the MCR after single injection 


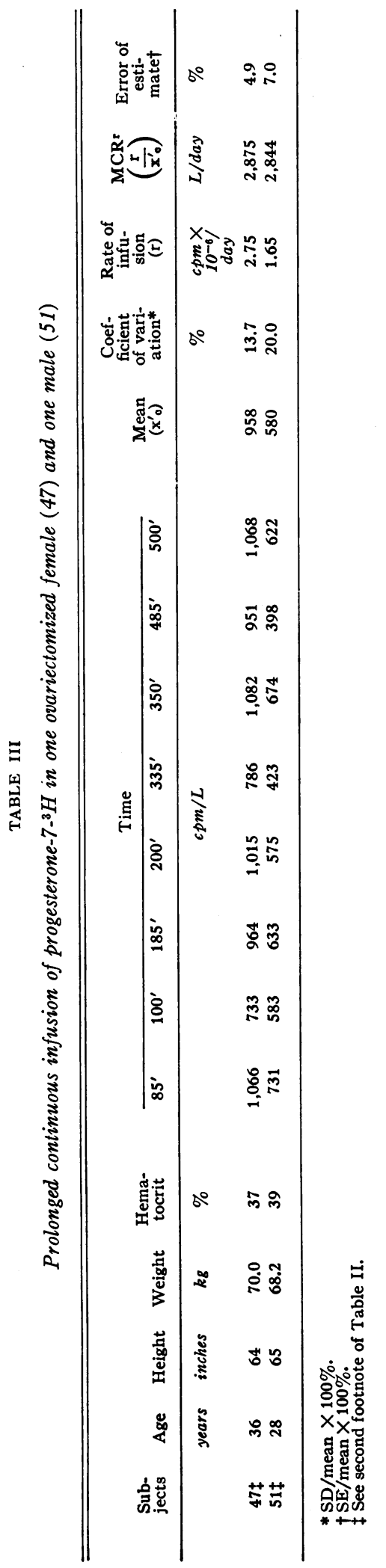

indicate that the integration of more than two exponentials may give more accurate values. Also, in practice continuous infusion is preferred, because random errors can be calculated more easily.

In ten males the $\mathrm{MCR}^{\mathbf{r}}$ was $2,081 \pm 137(\mathrm{SE})$, and in eleven ovariectomized females the $\mathrm{MCR}^{\mathbf{r}}$ was $2,173 \pm 175$ (SE) as estimated by continuous infusion. There was no significant difference between these values. The coefficient of variation of the $\mathrm{MCR}^{\mathrm{r}}$ of the males was $21 \%$, and that of the ovariectomized females was $27 \%$ (Table IV).

The curves plotted for the means $\left(\mathrm{A}^{\prime}, \mathrm{B}^{\prime}, \alpha\right.$, and $\beta$ ) of males and ovariectomized females are shown in Figure 1. The $t_{\frac{1}{2}}$ of the first portion of the curve $(1,000 / \alpha)$ has a mean value of 1.68 minutes for males and 0.96 minute for ovariectomized females. The $t_{1}$ of final straight line disappearance $(1,000 / \beta)$ has a mean value of 15.8 minutes for males and 10.7 minutes for ovariectomized females. The experiments that had plasma determinations at 50 and 70 minutes had $t_{1}$ of 24 and 26 minutes ( 9 and 17 ), and their $\mathrm{MCR}^{\mathrm{R}}$ were 2,069 and 1,359 , both well in the range of results of the continuous infusion experiments.

The mean initial volume of distribution for the females was $\mathrm{V}^{\mathrm{I}}$ 9.2 L and for the males $\mathrm{V}^{\mathrm{I}} 13.2 \mathrm{~L}$. The males were larger than the females, the mean weight of the females being $75.4 \mathrm{~kg}$ (in spite of one weighing $113.6 \mathrm{~kg}$ ) and that of the males $82.7 \mathrm{~kg}$. Although there were not enough values to determine a regression analysis of weight and

TABLE IV

Summary of metabolic clearance rates measured by single injection $\left(M C R^{R}\right)$ and continuous infusion ( $\left.M C R^{r}\right)$ methods in 14 ovariectomized females and 16 males

\begin{tabular}{ccc}
\hline \hline Subjects & MCR & $\begin{array}{c}\text { Coeffi- } \\
\text { cient of } \\
\text { variation }\end{array}$ \\
\hline Ovariectomized & $L /$ day & $\%$ \\
females (3)* & $2,428 \pm 322 \dagger$ & 23 \\
Males (6) & $2,450 \pm 437$ & 43 \\
Mean MCR & $2,443 \pm 294$ & 33 \\
Overiectomized & MCR & \\
females (11) & $2,173 \pm 175$ & 27 \\
Males (10) & $2,081 \pm 137$ & 21 \\
Mean MCRr & $2,129 \pm 110$ & 24 \\
Combined mean & $2,223 \pm 114$ & 28
\end{tabular}

* Number of subjects.

$\dagger \pm$ denotes standard error. 


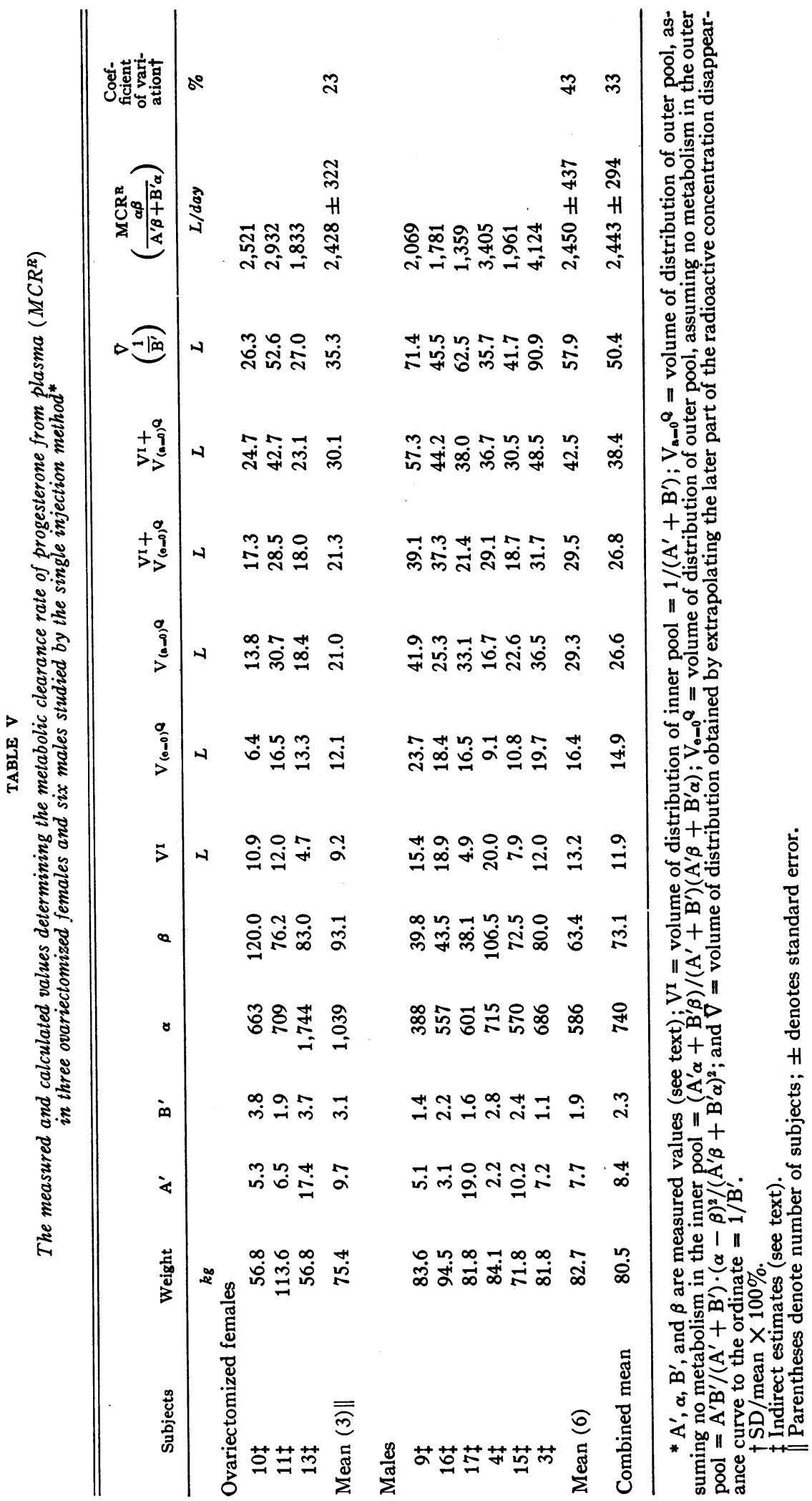


$\mathrm{V}^{\mathrm{I}}$, there was a significant rank correlation between weight and $V^{I}(p<0.025)$ in the males, and apparently the same applied to the few females (Table V).

The apparent volume $(\overline{\mathrm{V}})$ measured from the extrapolation of the final slope of equilibrium was (1/B) $50.4 \mathrm{~L}$, but this was not a very useful measurement. $\mathrm{V}^{\mathbf{Q}}$ can be calculated $\mathrm{V}_{\mathrm{a}=0^{\mathrm{Q}}}=26.6$ $\mathrm{L}(\mathrm{a}=0$; metabolism in the inner compartment is zero), and $\mathrm{V}_{\mathrm{e}=0^{\mathrm{Q}}}=14.9 \mathrm{~L}(\mathrm{e}=0$; metabolism in the outer compartment is zero). The true value of $\mathrm{V}^{Q}$ therefore lies between 15 and $27 \mathrm{~L}$, and this cannot be calculated more precisely without a knowledge of relative metabolism in both compartments. The total volume $\left(\mathrm{V}^{\mathrm{I}}\right.$ and $\left.\mathrm{V}^{\mathrm{Q}}\right)$, which is the total body content of hormone divided by plasma concentration, has a range of 27 to $39 \mathrm{~L}$. In ovariectomized females the values were less, as shown in Table $\mathrm{V}$, but the number of observations was small.

The metabolic clearance rate of progesterone after single injection was $M^{2} R^{R} 2,428 \pm 322$ (SE) in ovariectomized females and $2,450 \pm 437$ (SE) in males. There was a difference of $<1 \%$ between the means. The coefficient of variation of determinations in the males was $43 \%$ and $23 \%$ in the ovariectomized females (Table V).

As there is no difference between the single injection and continuous infusion calculation of clearance rates for the individual groups of ovariectomized females and males, all the values can be pooled to arrive at the most critical assessment of whether there is a difference between ovariectomized females and males. Combined plasma clear-

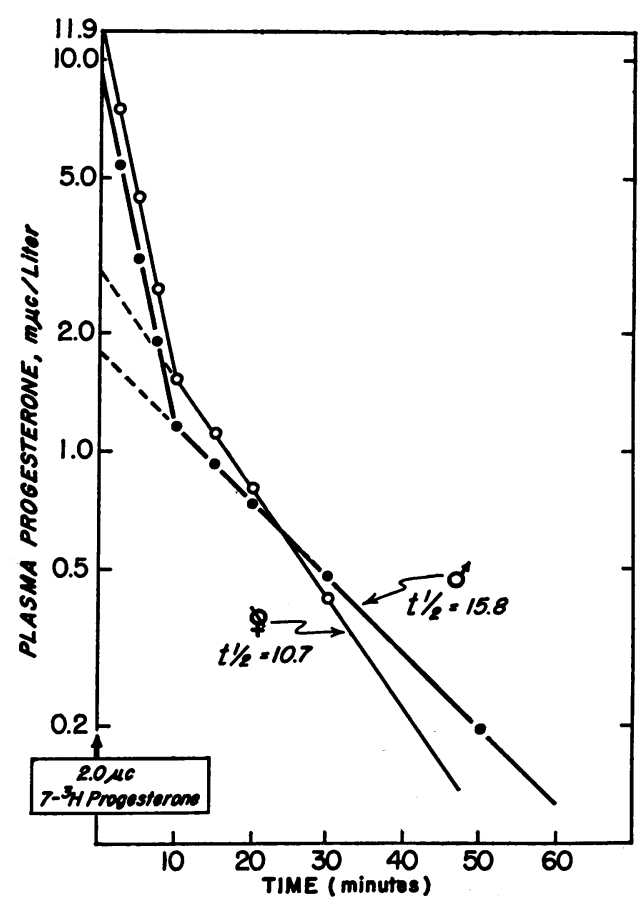

Fig. 1. The plasma disappearance curves of $2.0 \mu \mathrm{C}$ PROGESTERONE-7- ${ }^{3} \mathrm{H}$ INJECTED IN THREE OVARIECTOMIZED FEMALES ( $(q)$ AND SIX MALES ( $\left.\sigma^{*}\right)$ DRAWN FROM THE MEAN OF INDIVIDUAL EXPERIMENTS IN WHICH SINGLE POINTS WERE FITTED BY THE METHOD OF LEAST SQUARES.

ance for 16 males was $2,219 \pm 175(\mathrm{SE})$ and for 14 ovariectomized females $2,228 \pm 137$ (SE), which was not significantly different (Table IV).

In five continuous infusion experiments on males, whole blood concentration was measured at the same time as plasma (Table VI). The plasma/blood concentration had a mean value of

TABLE VI

The measured and calculated values determining the metabolic clearance rate of progesterone from blood (MCRr) in the same five males as Table I, measured by the continuous infusion method

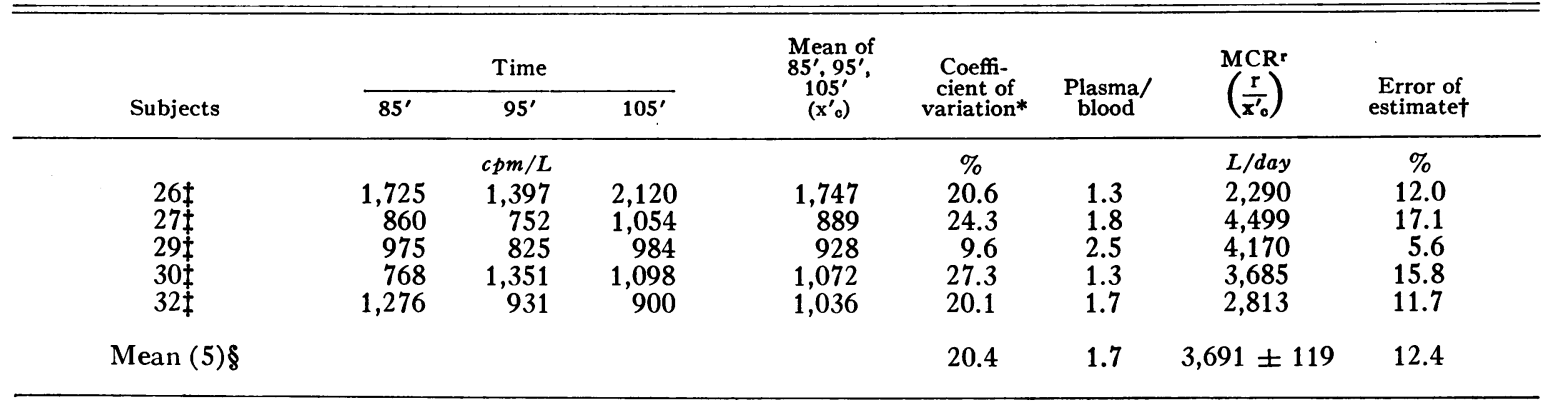

$* \mathrm{SD} /$ mean $\times 100 \%$.

$\dagger \mathrm{SE} / \mathrm{mean} \times 100 \%$.

† See second footnote to Table I.

$\S$ Parentheses denote number of subjects; \pm denotes standard error. 
$1.7 \pm 0.2$ (SE) with a mean hematocrit of $44 \%$, indicating that progesterone was entirely in the plasma. The mean $\mathrm{MCR}^{\mathrm{r}}$ for whole blood in the males was $3,691 \pm 119$ (SE). The hematocrit of the females (11 subjects) was $34.5 \%$; their whole blood clearance may be calculated to be 3,247 L per day by making the assumption that they have the same plasma blood ratio as the males.

\section{Discussion}

The rapid disappearance of progesterone from plasma is well known. The rate of disappearance of radioactivity from the plasma after the administration of progesterone-4- ${ }^{14} \mathrm{C}$ has been shown by Sandberg and Slaunwhite to have a $t_{\frac{1}{2}}$ of $20 \mathrm{~min}$ utes (9). Their value of $t_{3} 90$ minutes for subsequent equilibrium was believed to be for progesterone and its most rapidly formed metabolites. Reaction of the plasma with glucuronidase and sulfatase gave values of plasma radioactivity with an even slower disappearance. Haskins examined the disappearance of ultraviolet-absorbing material from the plasma of rabbits after the injection of $10 \mathrm{mg}$ of progesterone and found the value to be $t_{1} 4.9$ minutes. By biologic assay the value was $t_{1} 3.3$ minutes (10). Soiva, Haskins, and McCafferty showed the rapid disappearance of plasma radioactivity after the injection of 276 $\mu \mathrm{g}$ progesterone- $4-{ }^{14} \mathrm{C}(11)$. Nine minutes after the single injection of progesterone $-4-{ }^{14} \mathrm{C}$ Zander showed the presence in the plasma of pregnanolone

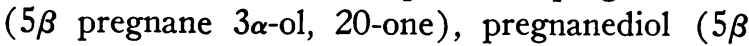
pregnane $3 \alpha$-20 $\alpha$-diol), and $20 \alpha$-hydroxy-4 pregnen, 3-one). Short and Eton (12) calculated $t_{\frac{1}{2}}$ to be 5 minutes in pregnant women after the removal of the placenta at Cesarean section. Short also showed in ewes a $t_{\frac{1}{2}}$ of 4 minutes after allowing 5 minutes for complete mixing (13). Comparison of these results with ours is difficult because of the lack of specificity of the measurement of progesterone in some of the reported work. In other studies, the $t_{\frac{1}{1}}$ has been measured at a greater time after the initial injection. In some reported papers, both the design of the experiments and nonspecificity of plasma radioactivity measurements make their results incomparable with ours. We could not conclude from these studies whether the rapid disappearance of administered progesterone from plasma and blood was due to the rate of its metabolism or the rapidity of its spread into a large volume throughout the body, perhaps because of the lipid solubility of progesterone. From the present data $\mathrm{V}^{\mathrm{I}}$ is about $12 \mathrm{~L}$ and $\mathrm{V}^{\mathrm{Q}}$ has a value between 15 and $27 \mathrm{~L}$, which is a comparatively small volume. Thus, it can be confirmed that the rapid disappearance of progesterone is caused by its rapid rate of metabolism.

Results show that either the single injection or continuous infusion method is valid for the measurement of the metabolic clearance rate of progesterone. However, the higher mean values for the $\mathrm{MCR}^{\mathrm{R}}$ after single injection in both ovariectomized women and in males indicate that more accurate values can be obtained by measuring concentrations at later times and integrating more than two exponentials. As indicated in Methods, the omission of a third exponential (or $\mathrm{C}^{\prime} / \gamma$ in the MCR calculation) would lead to a value for MCR that is too high. The continuous infusion method has advantages, in that less blood need be drawn, and equilibrium can be assessed in each case. It is easier to test for equilibrium than for straight line disappearance. Single injection, on the other hand, gives more information on volumes of distribution. Metabolic clearance rate can also be estimated from the production rate of progesterone and blood concentration $\left(\mathrm{P}^{\mathrm{I}} / \mathrm{i}\right)$. However, diurnal variation in blood concentration is not considered unless more than one sample is drawn. Also the only suitable metabolite, pregnanediol, is excreted slowly, and after the injection of labeled progesterone the radioactivity of this metabolite takes 4 days to collect. Pregnanediol is also not necessarily the specific metabolite of progesterone alone.

The MCR for progesterone in plasma of 2,100 $\mathrm{L}$ per day (continuous infusion estimation for males and ovariectomized females) is greater than the plasma hepatic blood flow of about $1,500 \mathrm{~L}$ per day. This indicates that progesterone must be cleared to a considerable extent by extrahepatic tissues. This has been suggested previously by Berliner and Wiest, who showed the rapid conversion of progesterone-4- ${ }^{14} \mathrm{C}$ to seven metabolites in the eviscerated rat (14). If the splanchnic extraction of progesterone is assumed to be $100 \%$, extrahepatic clearance would be about $600 \mathrm{~L}$ per day or about $50 \%$ of the splanchnic clearance. Actually, the splanchnic extraction of progesterone. 
has been measured directly by simultaneous assay of peripheral and hepatic venous plasmas and found to be about $70 \%$ (15). If this value is taken, the amount of splanchnic and extrasplanchnic clearance would be about equal. This is to be contrasted with aldosterone, where metabolic clearance rate is equivalent to hepatic blood flow, hepatic extraction of aldosterone is $95 \%$, and extrahepatic clearance is less than $20 \%$ of the splanchnic clearance.

The high clearance of progesterone does indicate high hepatic extraction. Preliminary estimates of hepatic extraction by direct measurement are high (about 70\%) (15). If this is true, it indicates that aldosterone and progesterone, which are bound mainly to albumin (16), are metabolized readily in spite of this binding, which is strong in the case of progesterone. Recently Seal, Makey, and Doe (17) reported that progesterone is strongly bound to corticosteroid-binding globulin (CBG) in human plasma. However, reliable calculations of the relative amounts bound to albumin and CBG in plasma have not yet been made.

The volumes of distribution of progesterone are not so great as those of aldosterone but larger than those of cortisol. This indicates that plasma albumin binding has little effect on its distribution, that progesterone binding by tissues is just as strong as its binding to plasma proteins, or both.

There is a slight difference in the values of distribution of ovariectomized females and males that is not statistically significant and may in part be a result of the difference in hematocrit between these two groups (females, hematocrit $=34 \%$; males, hematocrit $=44 \%)$. The plasma concentration of progesterone is about the same in the two groups (18).

From the plasma concentration in normal males of $0.028 \pm 0.004$ (SE) $\mu \mathrm{g}$ per $100 \mathrm{ml}$ (18) and the estimated urinary production rate of $4.5 \mathrm{mg}$ per day (19) or $3.2 \pm 0.49$ (SE) $\mathrm{mg}$ per day (20), it can be estimated that the plasma clearance rate in males would be about $14,000 \mathrm{~L}$ per day, which is greatly in excess of cardiac output. Also, taking the most reliable MCR value, as from the continuous infusion results, a plasma production rate in males can be calculated as $0.59 \mathrm{mg}$ per day, which is much lower than the corresponding urinary production rates (mean value, $3.8 \mathrm{mg}$ per day). This discrepancy in plasma and urinary production rates was the first reported for any steroid (1). In previous publications, the MCR of progesterone was reported as about 3,000 L per day, which was erroneously high due to adsorption of the tritiated progesterone in the tubing used for infusion. However, the correct MCR values of $2,100 \mathrm{~L}$ per day as reported have increased the discrepancy in the urinary and plasma production rates. The plasma concentration of progesterone in the male used in this calculation has recently been confirmed by a reliable gas chromatographic method (21). These estimated urinary production rates were determined from the specific activity of pregnanediol in the urine after the injection of radioactive progesterone. However, by using a simultaneous injection of pregnenolone- ${ }^{8} \mathrm{H}$ and progesterone $-{ }^{14} \mathrm{C}$, Arcos, Gurpide, Vande Wiele, and Lieberman (22) have reported that progesterone is not the specific and only precursor of $5 \beta$ pregnane, $3 \alpha-20 \alpha$-diol in the male and ovulating females; this confirms that measurement of progesterone production rates (1) from pregnanediol is invalid in the male and suggests that this may also be the case in the female.

It was also suggested (1) that discrepancies in plasma and urinary production rates could be due to conversion of a precursor to the hormone in an outer compartment where the hormone is irreversibly metabolized to some extent and the urinary metabolite is formed. Since then this has been shown to be a likely explanation of the discrepancies in the plasma and urinary production rates of testosterone $(23,24)$ and androstenedione (25).

The plasma concentration of progesterone in ovariectomized females is $0.038 \pm 0.004$ (SE) $\mu \mathrm{g}$ per $100 \mathrm{ml}$ (18) leading to a calculated plasma production rate of $0.80 \pm 0.09$ ( $\mathrm{SE}$ ) $\mathrm{mg}$ per day. Urinary production rates in similar subjects have been estimated as $1.1 \pm 0.07$ (SE) $\mathrm{mg}$ per day (20). Although the urinary production rates are probably significantly higher than the plasma production rates, the difference in the values is much smaller than in males and could possibly be accounted for by differences in circadian variation in plasma concentrations and metabolic clearance rates. Similarly, the plasma concentrations in pre- and post-ovulatory normal females are 0.14 and $1.05 \mu \mathrm{g}$ per $100 \mathrm{ml}(18,26)$, which are similar to those recently reported by Van der Molen 
and Groen (21) leading to calculated plasma production rates of 2.9 and $22.1 \mathrm{mg}$ per day, respectively, assuming that the MCR is $2,100 \mathrm{~L}$ per day in normal females. Urinary production rates in the pre- and post-ovulatory female have been estimated as 5.0 and $30 \mathrm{mg}$ per day (27). Again the discrepancy in the urinary and plasma production rates is not so great as in the male, but is large enough to warrant caution in using urinary pregnanediol values in the normal female as accurate indexes of circulating progesterone concentrations. This agrees with the conclusions of Arcos and co-workers (22).

It should be noted that the plasma production rates for all subjects calculated here are lower than those quoted in a previous discussion (18) because of the use of the lowered MCR value for progesterone.

Probably the major usefulness of clearance rate studies will be to calculate the blood production rates from clearance rate and blood concentration (3). This avoids the difficulties of the interpretation of calculated urinary production rates (1).

\section{Summary}

A method has been presented for the estimation of the metabolic clearance rate (MCR) of progesterone by single injection and continuous infusion from plasma and whole blood.

A comparison of the single injection and continuous infusion methods of measuring MCR in males and ovariectomized females has been studied. The MCR measured by single injection $\left(\mathrm{MCR}^{\mathbf{R}}\right)$ is approximately equivalent to $\mathrm{MCR}$ measured by continuous infusion (MCR ${ }^{r}$ ) in both groups of subjects. However, the continuous infusion method is considered more accurate and practical.

The plasma $\mathrm{MCR}^{\mathrm{R}}$ for six males is $2,450 \pm 437$ (SE) L per day with a coefficient of variation of $43 \%$. The calculated total volume of distribution is 27 to $39 \mathrm{~L}$. The plasma $\mathrm{MCR}^{\mathbf{R}}$ for three ovariectomized females is $2,428 \pm 322$ (SE) L per day with a coefficient of variation of $23 \%$.

The plasma $\mathrm{MCR}^{\mathbf{r}}$ for ten males is $2,080 \pm 137$ (SE) L per day with a coefficient of variation of $21 \%$. The plasma $\mathrm{MCR}^{\mathbf{r}}$ for 11 ovariectomized females is $2,173 \pm 175$ (SE) L per day with a coefficient of variation of $27 \%$. There is no difference between males and ovariectomized females in the rate of clearance of progesterone from the plasma. The blood MCR $\mathrm{MCr}^{\mathrm{r}}$ five males is 3,691 $\pm 119 \mathrm{~L}$ per day; the plasma/blood ratio is $1.7 \pm$ 0.2 (SE) with a mean hematocrit of $44 \%$, which indicates that there is no appreciable progesterone in the red cells.

The rapid disappearance of progesterone has been shown to be a result of metabolism rather than distribution into a large volume. It is suggested that even in the presence of high hepatic extraction, progesterone is metabolized appreciably by the extrasplanchnic circulation.

The measured MCR values lead to calculated plasma production rates in the male that are much less than the corresponding urinary production rates. The discrepancy is less in ovariectomized females.

\section{Acknowledgment}

We acknowledge the technical assistance of Miss D. MacLean.

\section{References}

1. Tait, J. F. Review: the use of, isotopic steroids for the measurement of production rates in vivo. J. clin. Endocr. 1963, 23, 1285.

2. Yates, F. E., and J. Urquhart. Control of plasma concentrations of adrenocortical hormones. Physiol. Rev. 1962, 42, 359.

3. Tait, J. F., and S. Burstein. In vivo studies of steroid dynamics in Hormones, G. Pincus, Ed. New York, Academic Press, 1964, vol. 5.

4. Tait, J. F., B. Little, S. A. S. Tait, and C. Flood. The metabolic clearance rate of aldosterone in pregnant and nonpregnant subjects estimated by both single-injection and constant-infusion methods. J. clin. Invest. 1962, 41, 2093.

5. Purdy, R. H., M. Halla, and B. Little. Biosynthesis of $4-{ }^{14} \mathrm{C}$ - and $7 \alpha-{ }^{8} \mathrm{H}$-labeled $20 \alpha$-hydroxy-pregn-4en-3-one and $7 \alpha-{ }^{3} \mathrm{H}-3 \beta, 20 \alpha$-dihydroxypregn-5-ene. Steroids 1964, 4, 625.

6. Hamilton, W. F., and J. W. Remington. Comparison of the time concentration curves in arterial blood of diffusible and non-diffusible substances when injected at a constant rate and when injected instantaneously. Amer. J. Physiol. 1947, 148, 35.

7. Vande Wiele, R. L., P. C. MacDonald, E. Gurpide, and S. Lieberman. Studies on the secretion and interconversion of androgens. Recent Progr. Hormone Res. 1963, 19, 275.

8. Ayers, C. R., J. O. Davis, F. Lieberman, C. C. J. Carpenter, M. Berman, and A. Casper. The effects of chronic hepatic venous congestion on the metabolism of d,1-aldosterone and d-aldosterone. J. clin. Invest. 1962, 41, 884. 
9. Sandberg, A. A., and W. R. Slaunwhite, Jr. The metabolic fate of $\mathrm{C}^{14}$-progesterone in human subjects. J. clin. Endocr. 1958, 18, 253.

10. Haskins, A. L. Assay of circulating progesterone by ultraviolet spectroscopy. Proc. Soc. exp. Biol. (N. Y.) 1950, 73, 439.

11. Soiva, K. U., A. L. Haskins, and R. E. McCafferty. Radioactivity studies of human plasma after the intravenous administration of progesterone 4- $\mathrm{C}^{\mathbf{1 4}}$. Acta endocr. (Kbh.) 1959, 31, 400.

12. Short, R. V., and B. Eton. Progesterone in blood. III. Progesterone in the peripheral blood of pregnant women. J. Endocr. 1959, 18, 418.

13. Short, R. V. Progesterone in blood. I. The chemical determination of progesterone in peripheral blood. J. Endocr. 1958, 16, 415.

14. Berliner, D. L., and W. G. Wiest. The extrahepatic metabolism of progesterone in rats. $\mathrm{J}$. biol. Chem. 1956, 221, 449.

15. Little, B., J. Bougas, J. F. Tait, and S. A. S. Tait. The hepatic extraction of aldosterone $7-\mathrm{H}^{3}$ and progesterone $7-\mathrm{H}^{3}$ (abstract). Program of 45 th Meeting, The Endocrine Society, June 1963, p. 23.

16. Westphal, U., and B. D. Ashley. Steroid-protein interactions. IV. Influence of functional groups in $\Delta^{4}$-3-ketosteroids on interaction with serum albumin and $\beta$-lactoglobulin. J. biol. Chem. 1958, 233, 57.

17. Seal, U. S., D. Makey, and R. P. Doe. Progesterone binding by human serum proteins: the role of corticosteroid-binding globulin (CBG) (abstract). Program of 46th Meeting, The Endocrine Society, June 1964, p. 62.

18. Riondel, A., J. F. Tait, S. A. S. Tait, M. Gut, and B. Little. Estimation of progesterone in human peripheral blood using ${ }^{85} \mathrm{~S}$-thiosemicarbazide. J. clin. Endocr. 1965, 25, 229.

19. Romanoff, L. P., C. W. Morris, P. Welch, M. P. Grace, and G. Pincus. Metabolism of progesterone-
$4-C^{14}$ in young and elderly men. J. clin. Endocr. 1963, 23, 286.

20. Little, B., J. F. Tait, W. P. Black, and S. A. S. Tait. The secretion rate and metabolic clearance rate of progesterone $7-\mathrm{H}^{3}$ in men and ovariectomized women (abstract). Program of 44th Meeting, The Endocrine Society, June 1962, p. 17.

21. Van der Molen, H. J., and D. Groen. Determination of progesterone in human peripheral blood using gas-liquid chromatography with electron capture detection. J. clin. Endocr. 1965, 25, 1625.

22. Arcos, M., E. Gurpide, R. L. Vande Wiele, and S. Lieberman. Precursors of urinary pregnanediol and their influence on the determination of the secretory rate of progesterone. J. clin. Endocr. 1964, 24, 237.

23. Tait, J. F., and R. Horton. Some theoretical considerations on the significance of the discrepancy in urinary and blood production rate estimates of steroid hormones particularly in those of testosterone in young women. Steroids 1964, 4, 365.

24. Hudson, B., J. P. Coghlan, A. Dulmanis, and $M$. Wintour. The measurement of testosterone in biological fluids in the evaluation of androgen activity. Proceedings of the Second International Congress of Endocrinology, Part II. London, Excerpta Medica Foundation, 1965, p. 1127.

25. Horton, R., and J. F. Tait. Androstenedione produc-. tion and interconversion rates measured in peripheral blood and studies on the possible site of its conversion to testosterone. J. clin. Invest. 1966, 45, 301.

26. Woolever, C. A. Daily plasma progesterone levels during the menstrual cycle. Amer. J. Obstet. Gynec. 1963, 85, 981.

27. Dominguez, O. V., G. D. Francois, M. Watanabe, and S. Solomon. Progesterone secretion in man (abstract). Program of 44th Meeting, The Endocrine Society, June 1962, p. 17. 